\section{(6) OPEN ACCESS}

\title{
Long-term efficacy and safety in patients with rheumatoid arthritis continuing on SB4 or switching from reference etanercept to SB4
}

\author{
Paul Emery, ${ }^{1,2}$ Jiří Vencovský, ${ }^{3}$ Anna Sylwestrzak, ${ }^{4}$ Piotr Leszczyński, ${ }^{5}$ \\ Wieslawa Porawska, ${ }^{6}$ Barbara Stasiuk, ${ }^{7}$ Joanna Hilt, ${ }^{8}$ Zdenka Mosterova, ${ }^{9}$ \\ Soo Yeon Cheong, ${ }^{10}$ Jeehoon Ghil ${ }^{10}$
}

\begin{abstract}
Handling editor Tore K Kvien
- Additional material is published online only. To view, please visit the journal online (http://dx.doi.org/10.1136/ annrheumdis-2017-211591).
\end{abstract}

For numbered affiliations see end of article.

Correspondence to Professor Paul Emery, Leeds Institute of Rheumatic and Musculoskeletal Medicine, University of Leeds, Chape Allerton Hospital, Chapeltown Road, Leeds LS7 4SA, UK; p.emery@leeds.ac.uk

Received 3 April 2017 Revised 12 July 2017 Accepted 18 July 2017 Published Online First 9 August 2017

\section{ABSTRACT}

Objectives SB4 (Benepali, Brenzys) is a biosimilar of reference etanercept (ETN). In a randomised, doubleblind, 52-week study, SB4 demonstrated comparable efficacy and safety to ETN in patients with rheumatoid arthritis (RA). The open-label extension period evaluated long-term efficacy, safety and immunogenicity when continuing SB4 versus switching from ETN to SB4.

Methods In the randomised, double-blind phase, patients received weekly subcutaneous administration of $50 \mathrm{mg}$ SB4 or ETN with background methotrexate for up to 52 weeks. Patients in the Czech Republic and Poland who completed the 52-week visit were enrolled in the open-label extension period and received SB4 for 48 additional weeks. Efficacy, safety and immunogenicity were assessed up to week 100.

Results of 245 patients entering the extension period, 126 continued to receive SB4 (SB4/SB4) and 119 switched to SB4 (ETN/SB4). American College of Rheumatology $(A C R)$ response rates were sustained and comparable between SB4/SB4 and ETN/SB4 with ACR20 response rates at week 100 of $77.9 \%$ and $79.1 \%$, respectively. Other efficacy results, including radiographic progression, were also comparable between the groups. After week 52, rates of treatment-emergent adverse events were $47.6 \%$ (SB4/SB4) and $48.7 \%$ (ETN/SB4); one patient/group developed non-neutralising antidrug antibodies. No cases of active tuberculosis or injectionsite reactions were reported during the extension period. One patient (SB4/SB4) died of hepatic cancer.

Conclusions SB4 was effective and well tolerated over 2 years in patients with RA. Efficacy, safety and immunogenicity were comparable between the SB4/SB4 and ETN/SB4 groups, showing no risk associated with switching patients from ETN to SB4.

Trial registration number NCT01895309; 2012005026-30

\section{INTRODUCTION}

The tumour necrosis factor inhibitor etanercept was the first approved biologic disease-modifying antirheumatic drug and allowed for a major advance in the treatment of rheumatoid arthritis (RA). ${ }^{1}$ Eighteen years since its approval, etanercept continues to play a key role in RA management, having demonstrated efficacy and a manageable safety profile in both clinical trial and real-world settings. ${ }^{1}$ Other current indications for etanercept include juvenile idiopathic arthritis, psoriatic arthritis, ankylosing spondylitis, non-radiographic axial spondyloarthritis (European Union only), plaque psoriasis and paediatric psoriasis (USA only). ${ }^{23}$

SB4 (Benepali, Samsung Bioepis UK Limited, Surrey, UK; Brenzys, Samsung Bioepis, Republic of Korea) is a biosimilar of reference etanercept (ETN). The structural, physicochemical and biological quality attributes of SB4 have been shown to be highly similar to ETN in a comprehensive comparability exercise designed as part of the European Medicines Agency's rigorous approval pathway. ${ }^{4}$ A phase 1 study in healthy subjects demonstrated pharmacokinetic equivalence between SB4 and ETN $^{5}$; a phase 3 study (NCT01895309; EudraCT 2012-005026-30) in patients with moderate to severe RA despite treatment with methotrexate (MTX) demonstrated equivalent efficacy in terms of American College of Rheumatology 20\% response rate (ACR20) at the 24-week interim analysis (SB4, 78.1\%; ETN, 80.3\%) ${ }^{6}$ and at week 52 (SB4, 80.8\%; ETN, 81.5\%). ${ }^{7}$ Safety was generally comparable between SB4 and ETN. ${ }^{67}$

SB4 has been approved for treatment of RA, psoriatic arthritis, ankylosing spondylitis, non-radiographic axial spondyloarthritis and plaque psoriasis in the European Union. ${ }^{89}$ However, an important consideration for prescribing physicians is whether switching from ETN to SB4, which may occur in clinical practice, can be achieved without detriment to safety and efficacy. We analysed data from the open-label extension period of the phase 3 study to evaluate the efficacy, safety and immunogenicity of continuing SB4 (SB4/SB4) versus switching from ETN to SB4 (ETN/SB4). Long-term safety and efficacy were assessed up to week 100.

\section{METHODS}

\section{Study design and patients}

Patients with moderate to severe RA despite treatment with MTX were eligible to enrol in this phase 3, randomised, double-blind, multicentre study, which included an open-label extension period. Detailed patient inclusion/exclusion criteria were previously published. $^{6}$ During the double-blind period, patients were randomised $1: 1$ to receive subcutaneous SB4 $50 \mathrm{mg}$ or ETN $50 \mathrm{mg}$ once weekly for 52 weeks. Patients in the Czech Republic or Poland who completed the scheduled 52-week visit were enrolled in the open-label, single-arm 
extension period. During the extension period, patients from the SB4 group continued to receive SB4 (SB4/SB4), and patients from the ETN group switched to SB4 $50 \mathrm{mg}$ (ETN/SB4) once weekly for an additional 48 weeks. All patients took a stable dose of MTX (10-25 mg/week) from 4 weeks before screening until the end-of-treatment visit for the extension period. For patients who entered the extension period, efficacy was assessed at weeks 52, 76 and 100, and safety was assessed at all visits during treatment and at 4 weeks after treatment (or after the early termination visit).

\section{Endpoints}

Efficacy endpoints for the extension period included ACR20/50/70 response ( $\geq 20 \% / 50 \% / 70 \%$ improvement, respectively, from baseline in ACR response criteria), European League Against Rheumatism (EULAR) response and disease activity score based on a 28-joint count (DAS28). Physical function was assessed using the Health Assessment Questionnaire-Disability Index (HAQ-DI). For patients who entered the extension period, radiographs of the hands and feet obtained at weeks 0,52 and 100 were evaluated by a single reader to determine the modified Total Sharp Score (mTSS), which is the sum of the joint erosion and joint space narrowing (JSN) scores. ${ }^{10}$ Post hoc assessments included the proportions of patients achieving low disease activity (LDA) and remission based on the Simplified Disease Activity Index (SDAI), Clinical Disease Activity Index (CDAI) and DAS28 and the proportions achieving Boolean-based remission (defined as $\leq 1$ swollen and $\leq 1$ tender joint, C-reactive protein $\leq 1 \mathrm{mg} / \mathrm{dL}$ and patient global visual analogue scale score $\leq 1$ using a $0-10$ scale). Safety endpoints included the incidence of treatment-emergent adverse events (TEAEs) and adverse events (AEs) of special interest (serious infections and active tuberculosis). Immunogenicity was assessed by determining the incidence of antidrug antibodies (ADAs) and neutralising antibodies; ADAs were detected in serum samples using an electrochemiluminescence bridging assay (Meso Scale Discovery, Maryland, USA), double-antigen format with acid dissociation and neutralising antibodies were measured using a competitive ligand-binding assay. ${ }^{6}$

\section{Statistical analysis}

All data were analysed descriptively. Efficacy and safety data were analysed in the extended population, which comprised all patients who provided informed consent for the open-label extension period and received $\geq 1$ dose of study medication in the open-label extension period. Efficacy data obtained up to week 52 were analysed retrospectively in this population. No imputation was made for missing data. Analyses were performed using SAS software, V.9.2 or higher (SAS Institute, Cary, North Carolina, USA).

\section{RESULTS}

\section{Patients}

A total of 245 patients, including 126 who continued on SB4 and 119 who switched to SB4 from ETN, enrolled in the extension period. All patients received $\geq 1$ dose of study drug during the extension period and were included in this analysis. Patient disposition is shown in figure $1 ; 94.7 \%$ of patients $(232 / 245)$ who entered the extension period completed 100 weeks of treatment, with $5.6 \%$ of patients in the SB4/SB4 group and $5.0 \%$ of patients in the ETN/SB4 group withdrawing before week 100. Patient demographic and clinical characteristics were well balanced between the two groups (table 1).

\section{Efficacy}

ACR responses were comparable between the SB4/SB4 and ETN/ SB4 groups and were maintained from weeks 52 through 100, with $79.2 \% / 52.0 \% / 38.4 \%$ and $82.4 \% / 53.8 \% / 32.8 \%$ of patients achieving ACR20/50/70 in each group, respectively, at week 52\%

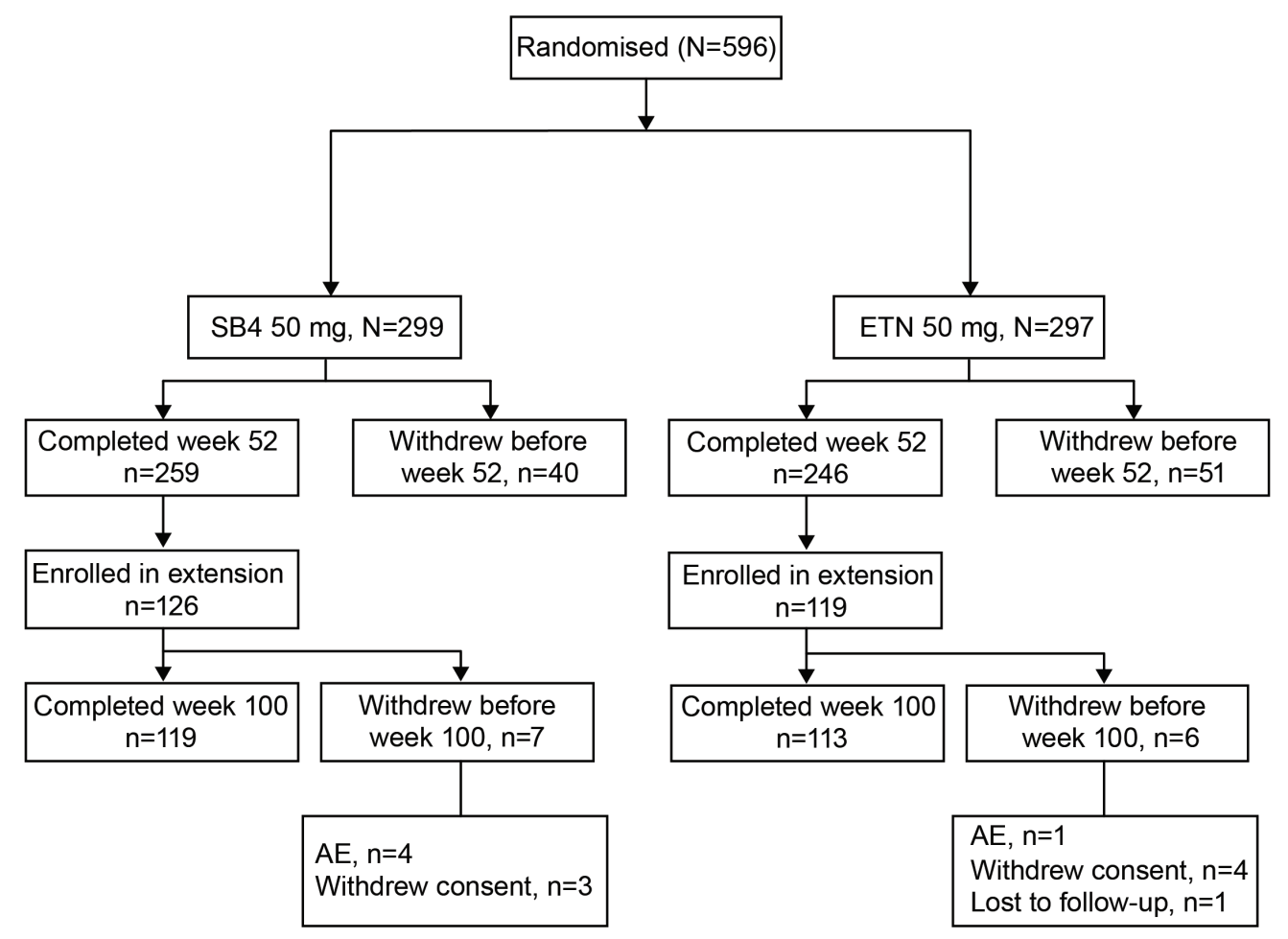

Figure 1 Patient disposition. AE, adverse event; ETN, reference etanercept. 
and $77.9 \% / 59.8 \% / 42.6 \%$ and $79.1 \% / 60.9 \% / 41.7 \%$ of patients achieving ACR20/50/70 in each group, respectively, at week 100 (figure 2). ACR responses were also comparable between the two groups in the retrospective analysis of this population during the initial 52-week treatment period. Other efficacy results at week 100 are shown in table 2. At this time point, the proportion of patients who had moderate or good EULAR responses; the proportion who achieved LDA and remission based on DAS28, SDAI or CDAI criteria and the proportion who

Table 1 Patient baseline demographics and disease characteristics at baseline and week 52 (extended population)

\begin{tabular}{|c|c|c|}
\hline Variable & $\begin{array}{l}\text { SB4/SB4 } \\
(n=126)\end{array}$ & $\begin{array}{l}\text { ETN/SB4 } \\
(n=119)\end{array}$ \\
\hline Age, years & $49.9(12.05)$ & $52.1(10.91)$ \\
\hline Women, n (\%) & $107(84.9)$ & $100(84.0)$ \\
\hline White, $n(\%)$ & $126(100.0)$ & $118(99.2)$ \\
\hline $\mathrm{BMI}, \mathrm{kg} / \mathrm{m}^{2}$ & $26.7(5.80)$ & $26.1(5.05)$ \\
\hline Disease duration, years & $5.7(3.94)$ & $5.8(4.18)$ \\
\hline Duration of MTX use, months & $46.0(35.63)$ & $43.9(39.81)$ \\
\hline Weekly dose of MTX, mg & $16.9(4.92)$ & $16.5(4.91)$ \\
\hline \multicolumn{3}{|l|}{ Swollen joint count (0-66) } \\
\hline Baseline & $14.4(7.25)$ & $14.4(7.74)$ \\
\hline Week 52 & $2.9(4.84)$ & $2.8(4.30)$ \\
\hline \multicolumn{3}{|l|}{ Tender joint count (0-68) } \\
\hline Baseline & $21.0(9.96)$ & $21.4(11.08)$ \\
\hline Week 52 & $5.0(7.11)$ & $5.6(7.86)$ \\
\hline \multicolumn{3}{|l|}{ Physician VAS (0-100) } \\
\hline Baseline & $62.4(16.35)$ & $63.6(15.25)$ \\
\hline Week 52 & $16.8(14.47)$ & $18.8(15.27)$ \\
\hline \multicolumn{3}{|l|}{ Patient VAS (0-100) } \\
\hline Baseline & $58.9(19.75)$ & $61.5(18.08)$ \\
\hline Week 52 & $24.9(20.97)$ & $26.8(19.62)$ \\
\hline \multicolumn{3}{|l|}{ Patient pain VAS (0-100) } \\
\hline Baseline & $59.0(21.38)$ & $60.5(20.22)$ \\
\hline Week 52 & $25.8(21.86)$ & $27.0(21.32)$ \\
\hline \multicolumn{3}{|l|}{ HAQ-DI (0-3) } \\
\hline Baseline & $1.38(0.555)$ & $1.45(0.597)$ \\
\hline Week 52 & $0.68(0.585)$ & $0.74(0.651)$ \\
\hline \multicolumn{3}{|l|}{ DAS28 } \\
\hline Baseline & $6.22(0.908)$ & $6.26(0.877)$ \\
\hline Week 52 & $3.40(1.179)$ & $3.49(1.119)$ \\
\hline \multicolumn{3}{|l|}{ SDAI } \\
\hline Baseline & $37.01(12.037)$ & 37.65 (12.052) \\
\hline Week 52 & $10.04(8.589)$ & $10.38(8.713)$ \\
\hline \multicolumn{3}{|l|}{ CDAI } \\
\hline Baseline & $35.85(11.586)$ & $36.45(11.672)$ \\
\hline Week 52 & $9.41(8.249)$ & $10.01(8.670)$ \\
\hline \multicolumn{3}{|l|}{ CRP, mg/L } \\
\hline Baseline & $11.5(15.71)$ & $12.0(16.35)$ \\
\hline Week 52 & $6.2(15.84)$ & $3.8(5.47)$ \\
\hline \multicolumn{3}{|l|}{$\mathrm{ESR}, \mathrm{mm} / \mathrm{h}$} \\
\hline Baseline & $41.9(23.26)$ & $41.7(19.53)$ \\
\hline Week 52 & $24.5(18.63)$ & $22.2(16.21)$ \\
\hline Rheumatoid factor positive, $\mathrm{n}(\%)$ & 99 (78.6) & 89 (74.8) \\
\hline
\end{tabular}

Values represent mean (SD) unless otherwise specified.

$\mathrm{BMI}$, body mass index; CDAl, Clinical Disease Activity Index; CRP, C-reactive protein; DAS28, disease activity score based on a 28-joint count; ESR, erythrocyte sedimentation rate; ETN, reference etanercept; $H A Q-D I$, Health Assessment Questionnaire-Disability Index; MTX, methotrexate; SDAI, Simplified Disease Activity Index; VAS, visual analogue scale.

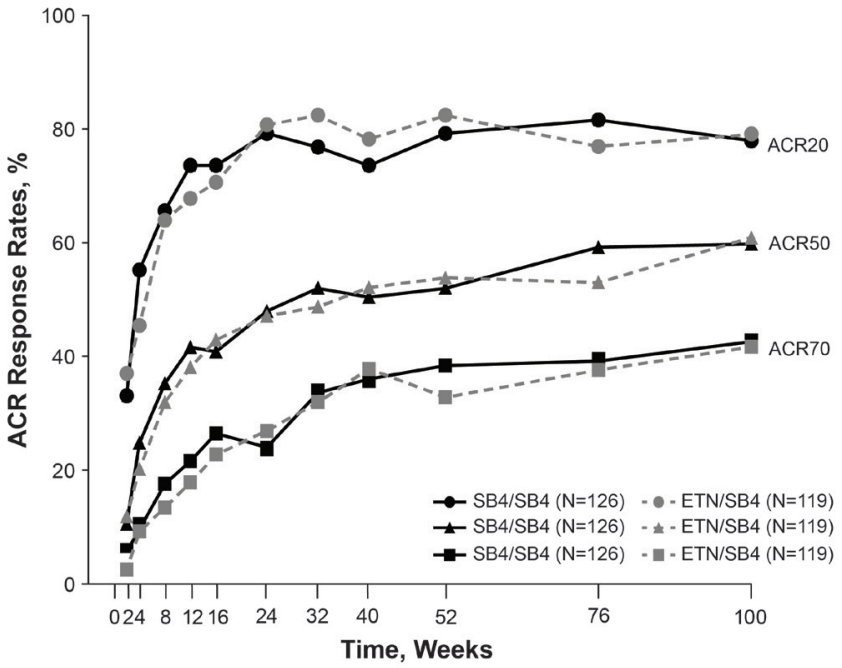

Figure 2 American College of Rheumatology (ACR) response rates up to week 100 (extended population). ACR20/50/70=American College of Rheumatology 20\%/50\%/70\% response criteria; ETN, reference etanercept.

achieved Boolean-based remission were comparable between the SB4/SB4 and ETN/SB4 groups. Further, throughout the study, DAS28, SDAI, CDAI and HAQ-DI scores were also comparable between the two groups (see figure in the online supplementary material 1). The main factor driving the improvement in DAS28 score was the reduction in swollen and tender joint counts; these components demonstrated the largest percentage improvements from baseline during the extension period. At week 100, radiographic progression was comparable and minimal (figure 3), with mean (SD) change from baseline mTSS values of 0.48 (4.053) for the SB4/SB4 group and 1.00 (5.563) for the ETN/SB4 group (table 2). Summary of structural joint damage for each visit can be found in table S1 in the online supplementary material 1.

\section{Safety}

Safety after week 52 was generally comparable between the SB4/ SB4 and ETN/SB4 groups (table 3). This extension study was not adequately powered to showsimilar safety and imbalance might be expected as shown in the incidence of serious TEAEs, RA, viral infection, laryngitis and hypertension. Serious infection was reported in one patient in each treatment group, and there were no reports of active tuberculosis. Also during the extension period, no injection-site reactions were reported. One patient in the SB4/SB4 group died of hepatic cancer, which was considered to be related to the study drug. One patient in each treatment group developed non-neutralising ADAs after week 52 (see table S2 in the online supplementary material 1). Both patients had a low titre, and the ADAs did not affect efficacy. The patient in the SB4/SB4 group tested positive at week 100 with a titre of 1 and achieved an ACR50 response at week 100. The patient from the ETN/SB4 group tested positive at week 76 with a titre of $<1$ and achieved an ACR70 response at week 100.

\section{DISCUSSION}

This open-label extension period of a phase 3, randomised, double-blind study evaluated the long-term efficacy, safety and immunogenicity of SB4 in patients with moderate to severe RA despite MTX treatment and compared outcomes between patients who continued SB4 $(n=126)$ and those who switched from ETN to SB4 $(n=119)$. Results showed SB4 to be effective 


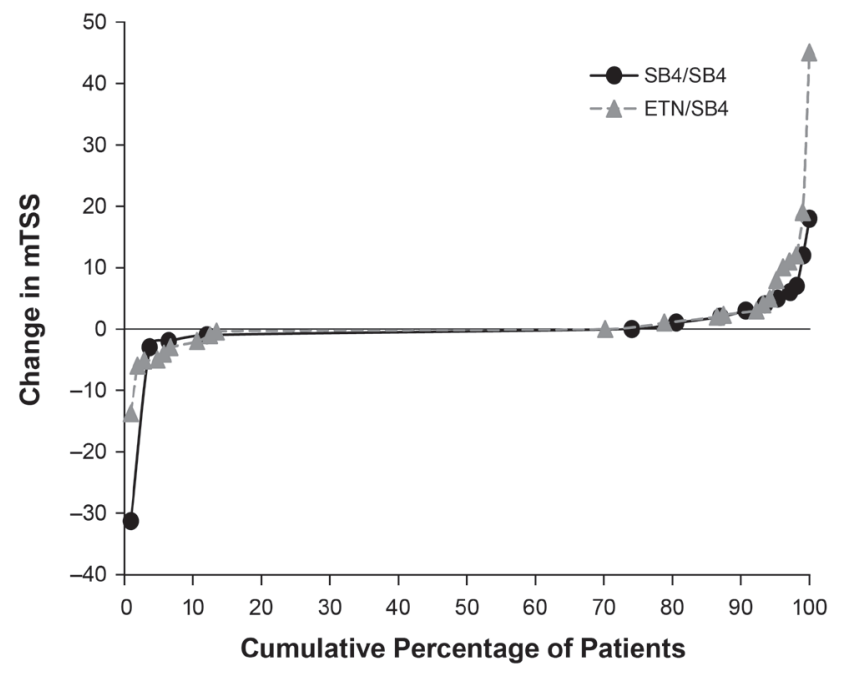

Figure 3 Cumulative probability of mTSS change from baseline at week 100 (extended population). Data based on patients with available radiographic assessment results at each visit. ETN, reference etanercept; mTSS, modified Total Sharp Score.

\begin{tabular}{|c|c|c|}
\hline & $\begin{array}{l}\text { SB4/SB4 } \\
(n=126)\end{array}$ & $\begin{array}{l}\text { ETN/SB4 } \\
(n=119)\end{array}$ \\
\hline \multicolumn{3}{|l|}{ EULAR response, $\mathrm{n} / \mathrm{N}^{*}(\%)$} \\
\hline Good & $59 / 121(48.8)$ & $63 / 115(54.8)$ \\
\hline Moderate & $54 / 121(44.6)$ & $40 / 115(34.8)$ \\
\hline No response & $8 / 121(6.6)$ & $12 / 115(10.4)$ \\
\hline \multicolumn{3}{|l|}{ DAS28 } \\
\hline Improvement from baseline, mean (SD) & $2.9(1.5)$ & $3.0(1.5)$ \\
\hline \multicolumn{3}{|l|}{ Disease activity, $\mathrm{n} / \mathrm{N}^{*}(\%)$} \\
\hline Low $(\leq 3.2)$ & $60 / 122(49.2)$ & $63 / 115(54.8)$ \\
\hline Remission $(<2.6)$ & $37 / 122(30.3)$ & $40 / 115(34.8)$ \\
\hline \multicolumn{3}{|l|}{ SDAl score } \\
\hline Improvement from baseline, mean (SD) & $27.4(15.5)$ & $28.7(14.6)$ \\
\hline \multicolumn{3}{|l|}{ Disease activity, $\mathrm{n} / \mathrm{N}^{*}(\%)$} \\
\hline Low (>3.3 and $\leq 11)$ & $41 / 123(33.3)$ & $44 / 115(38.3)$ \\
\hline Remission $(\leq 3.3)$ & $38 / 123(30.9)$ & $39 / 115(33.9)$ \\
\hline \multicolumn{3}{|l|}{ CDAl score } \\
\hline Improvement from baseline, mean (SD) & $26.8(15.0)$ & $27.9(14.1)$ \\
\hline \multicolumn{3}{|l|}{ Disease activity, $n / N^{*}(\%)$} \\
\hline Low $(>2.8$ and $\leq 10)$ & $38 / 123(30.9)$ & $46 / 115(40.0)$ \\
\hline Remission $(\leq 2.8)$ & $40 / 123(32.5)$ & $33 / 115(28.7)$ \\
\hline Boolean-based remission, $\mathrm{n} / \mathrm{N}^{*}(\%)$ & $31 / 123(25.2)$ & $23 / 115(20.0)$ \\
\hline \multicolumn{3}{|l|}{ Radiographic results $\dagger$} \\
\hline $\begin{array}{l}\text { Change from baseline in JSN score, } \\
\text { mean (SD) }\end{array}$ & $0.19(1.98)$ & $0.39(2.86)$ \\
\hline $\begin{array}{l}\text { Change from baseline in joint erosion } \\
\text { score, mean (SD) }\end{array}$ & $0.28(2.57)$ & $0.61(3.08)$ \\
\hline $\begin{array}{l}\text { Change from baseline in mTSS, mean } \\
\text { (SD) }\end{array}$ & $0.48(4.05)$ & $1.0(5.56)$ \\
\hline
\end{tabular}

\footnotetext{
*Number of patients with available data at each time point.
}

tBased on number of patients who completed week 100 visit with available radiographic assessment results at weeks 0 and 100 (SB4/SB4, $n=108$; ETN/SB4, $\mathrm{n}=104)$.

CDAI, Clinical Disease Activity Index; DAS28, disease activity score based on a 28-joint count; ETN, reference etanercept; EULAR, European League Against Rheumatism; JSN, joint space narrowing; mTSS, modified Total Sharp Score; SDAI, Simplified Disease Activity Index. and well tolerated over 2 years. In patients who switched from ETN to SB4, comparable efficacy to the SB4/SB4 group was observed, with no new safety signals identified.

Among the patients entering the extension period, $94.4 \%$ in the SB4/SB4 group and $95.0 \%$ in the ETN/SB4 group completed an additional 48 weeks of SB4 treatment. The discontinuation rate due to lack of efficacy or TEAEs was very low, which suggests the long-term tolerability of SB4 treatment.

Efficacy outcomes in the extended population were comparable between the SB4/SB4 and ETN/SB4 groups at all visits up to week 100 , sustained from weeks 52 to 100 and unaffected by switching. Comparable inhibition of radiographic progression was previously reported after 52 weeks of treatment with SB4 or ETN (mean change in mTSS: 0.45 for SB4 vs 0.74 for ETN). ${ }^{7}$ In both groups, continued inhibition of radiographic progression was observed with an additional year of SB4 treatment, with mean changes from baseline in joint space narrowing and joint erosion of $<1$. This is consistent with historical results from randomised studies of etanercept with or without MTX in patients with RA. ${ }^{11-13}$ Two-year radiographic findings in patients with early RA continuing ETN+MTX therapy from year 1 showed a mean Sharp/van der Heijde score change of -0.02 and an improvement in mean 28-swollen joint count from 1.7 to $1.3 .{ }^{11}$ Similarly, 2-year data from the Canadian Methotrexate and Etanercept Outcome study showed that patients continuing ETN+MTX therapy after the first 6 months had mean changes from baseline in mTSS and JSN of 0.0 at month 24 and those switching to ETN monotherapy had mean changes from baseline in mTSS and JSN of $<1 .{ }^{12}$ Lastly, the Trial of Etanercept and Methotrexate with Radiographic Patient Outcomes (TEMPO) demonstrated mean changes from baseline in mTSS, joint erosion scores and JSN of $<1$ at years, 1, 2 and 3 of treatment with ETN+MTX. ${ }^{13}$

In the extension period, SB4 demonstrated a safety profile similar to that observed in the pivotal etanercept trials. ${ }^{11-13}$ There were no reports of active tuberculosis or injection-site reactions. One patient in each group reported a serious

Table 3 Safety after week 52 (extended population)

\begin{tabular}{lll}
\hline $\mathbf{n}(\%)$ & $\begin{array}{l}\text { SB4/SB4 } \\
(\mathbf{n}=126)\end{array}$ & $\begin{array}{l}\text { ETN/SB4 } \\
(\mathbf{n}=119)\end{array}$ \\
\hline$\geq 1$ TEAE & $60(47.6)$ & $58(48.7)$ \\
$\begin{array}{l}\text { Frequently reported TEAEs } \\
(\geq 3 \%)\end{array}$ & &
\end{tabular}

\begin{tabular}{lll}
$\begin{array}{l}\text { Upper respiratory tract } \\
\text { infection }\end{array}$ & $10(7.9)$ & $9(7.6)$ \\
\hline Pharyngitis & $9(7.1)$ & $5(4.2)$ \\
\hline Rheumatoid arthritis & $7(5.6)$ & $3(2.5)$ \\
\hline Bronchitis & $6(4.8)$ & $7(5.9)$ \\
Nasopharyngitis & $6(4.8)$ & $5(4.2)$ \\
Viral infection & $4(3.2)$ & $1(0.8)$ \\
\hline Laryngitis & $4(3.2)$ & $0(0.0)$ \\
\hline Hypertension & $1(0.8)$ & $5(4.2)$ \\
$\geq 1$ serious TEAE & $6(4.8)$ & $2(1.7)$ \\
TEAE leading to study drug & & \\
discontinuation & $4(3.2)$ & $2(1.7)$ \\
Serious infection & $1(0.8)$ & $1(0.8)$ \\
Active tuberculosis & $0(0.0)$ & $0(0.0)$ \\
Injection-site reaction* & $0(0.0)$ & $0(0.0)$ \\
Malignancy & $1(0.8)$ & $0(0.0)$ \\
Death & $1(0.8)$ & $0(0.0)$ \\
\hline
\end{tabular}

${ }^{*}$ TEAE with high-level group term of administration site reaction. tHepatic cancer, which was considered related to study drug. ETN, reference etanercept; TEAE, treatmentemergent adverse event. 
infection and one patient in the SB4/SB4 group died from hepatic cancer. After week 52, one patient in each group developed non-neutralising ADAs. The low incidence of non-neutralising ADAs observed in the study was expected given the low rates reported in short-term and long-term studies of etanercept-treated patients with RA (0\%-6\%). ${ }^{14-16}$ The ADAs developed prior to switching did not affect the efficacy or safety of SB4 in the ETN/SB4 group.

Results from this extended-period switching study showed maintenance of response after switching from ETN to SB4 with no newly identified safety issues (eg, no increase in immunogenicity or immune-related TEAEs of anaphylaxis, hypersensitivity or injection-site reactions). In extensions of PLANETRA (Program evaLuating the Autoimmune Disease iNvEstigational Drug cT-p13 in RA Patients) ${ }^{17}$ and PLANETAS (Program evaLuating the Autoimmune Disease iNvEstigational Drug cT-p13 in AS patients) ${ }^{18}$ which had similar study designs with the present study, switching from reference infliximab to the biosimilar infliximab CT-P13 was not associated with diminished efficacy or change in safety profile. These results are further corroborated by findings from the randomised, non-inferiority NOR-SWITCH study which demonstrated that switching to CT-P13 is not inferior to continued treatment with reference infliximab. ${ }^{19}$ In addition, data from the DANBIO registry where a nationwide switch took place, disease activity was not affected by the non-medical switch from the reference infliximab or ETN to CT-P13 or SB4, respectively. ${ }^{20}{ }^{21}$ Observations from these studies provide data relevant to clinical practice and support switching of reference products to biosimilars for non-medical reasons.

A retrospective analysis of our data was conducted for any potential anaphylaxis cases using related AEs (eg, pruritus, flushing, dyspnoea, hypotonia, syncope, incontinence, vomiting) and blood pressure (systolic blood pressure $<90 \mathrm{~mm} \mathrm{Hg}$ or $>30 \%$ decrease from baseline), as defined in the National Institute of Allergy and Infectious Diseases/Food Allergy Anaphylaxis Network criteria. ${ }^{22}$ No cases of potential anaphylaxis were identified based on this analysis.

The open-label nature of the extension period is a study limitation. Because patients were required to have completed the 52-week visit of the randomised, double-blind period in order to enrol in the extension, there was the potential for selection bias. However, baseline demographic and clinical characteristics were well balanced between the treatment groups and were representative of those in the core study. Moreover, disease activity at week 52 for patients who enrolled in the extension period was comparable with that of patients who did not enrol in the extension period (see table S3 in the online supplementary material 1), suggesting no selection bias towards patients who responded well to treatment. This switching study was designed to evaluate approximately 100 patients in each group to allow detection of an increase in the risk for injection site reactions to $1 \%$ or more. Therefore, the two countries with the largest number of enrolled patients (Poland and the Czech Republic) were selected to participate in the extension period. Although the extension period was not designed to compare equivalence statistically, it provides valuable data on switching from ETN to SB4 in patients with RA.

\section{CONCLUSIONS}

SB4 was well tolerated and effective over 2 years in patients with RA. Switching from ETN to SB4 was not associated with treatment-emergent issues such as loss of efficacy or increases in TEAEs or immunogenicity. Postmarketing surveillance and registry studies are ongoing to monitor the efficacy and safety of SB4 in various indications.

\section{Author affiliations}

Arthritis Research, Leeds Institute of Rheumatic and Musculoskeletal Medicine, University of Leeds, Leeds, UK

${ }^{2}$ NIHR Leeds Musculoskeletal Biomedical Research Unit, Leeds Teaching Hospitals NHS Trust, Leeds, UK

${ }^{3}$ Rheumatology, Institute of Rheumatology, Prague, Czech Republic

${ }^{4}$ Rheumatology, NZOZ Medica Pro Familia Sp. z 0.0., Warsaw, Poland

${ }^{5}$ Rheumatology, Poznan University of Medical Sciences, Poznan, Poland

${ }^{6}$ Rheumatology, Poznanski Osrodek Medyczny NOVAMED, Pultusk, Poland

${ }^{7}$ Rheumatology, Medicome Sp. z o.0, Oswiecim, Poland

${ }^{8}$ Rheumatology, Centrum Terapii Wspolczesnej J.M. Jasnorzewska sp. komandytowoakcyjna, Bialystok, Poland

${ }^{9}$ Rheumatology, Revmacentrum MUDr. Mostera sro, Brno, Czech Republic

${ }^{10}$ Clinical Sciences Division, Samsung Bioepis Co., Ltd., Incheon, Republic of Korea

Acknowledgements The authors thank the patients who were involved in this extension study, the study personnel who made this work possible and the study investigators. From the Czech Republic, this included L Podrazilova, M Sedlackova, G Simkova, H Brabcova, Z Urbanova, J Kopackova, P Vitek, and Z Stejfova. From Poland, this included I Janecka, A Rychlewska-Hanczewska, A Zielinska, S Daniluk, I Glogowska-Szelag, B Sliwowska, M Rell-Bakalarsk and B Grabowicz-Waśko.Editorial support for development of this manuscript was provided by Nicole Strangman, PhD, of C4 MedSolutions, LLC (Yardley, Pennsylvania, USA), a CHC Group company and funded by Samsung Bioepis Co., Ltd. Results included in this manuscript have been previously presented at the 2016 EULAR Congress and 2016 ACR/ARHP Annual Meeting.

Contributors PE, SYC, and JG contributed to the study conception and design, analysis and interpretation of data and agreed to be accountable for all aspects of the work in ensuring that questions related to the accuracy or integrity of any part of the work are appropriately investigated and resolved. JV, AS, PL, WP, BS, JH and ZM contributed to the acquisition of data. All the authors equally contributed to the drafting the manuscript and revising it critically for important intellectual content, final approval of the version published.

Funding This study was funded by Samsung Bioepis Co., Ltd.

Competing interests All authors received funding for clinical research from Samsung Bioepis. PE received consulting fees; JV, AS, PL, WP, BS, JH, and ZM received research grants and SYC and JG are full-time employee of Samsung Bioepis. In addition, $\mathrm{PE}$ reports receiving grant/research support from AbbVie and Pfizer and consultancy fees from AbbVie, Bristol-Myers Squibb, Pfizer, UCB, Merck Sharp \& Dohme, Roche, Novartis, Takeda and Lilly; JV served on speakers bureaus for UCB, Pfizer, AbbVie and Merck Sharp \& Dohme; PL received grant/research support from Roche, Merck Sharp \& Dohme, Janssen, Novo-Nordisk, UCB, Pfizer, Novartis, GlaxoSmithKline, Bristol-Myers Squibb, served as paid instructor for Novo-Nordisk and served on speakers bureaus for Merck Sharp \& Dohme, UCB, Roche and Amgen.

\section{Patient consent Obtained.}

Ethics approval This study was conducted in accordance with the Declaration of Helsinki and International Council for Harmonisation Good Clinical practice guidelines. Protocols were reviewed and approved by the independent ethics committee or institutional review board for each study centre. All patients provided written informed consent.

Provenance and peer review Not commissioned; externally peer reviewed.

Open Access This is an Open Access article distributed in accordance with the Creative Commons Attribution Non Commercial (CC BY-NC 4.0) license, which permits others to distribute, remix, adapt, build upon this work non-commercially, and license their derivative works on different terms, provided the original work is properly cited and the use is non-commercial. See: http://creativecommons.org/ licenses/by-nc/4.0/

(c) Article author(s) (or their employer(s) unless otherwise stated in the text of the article) 2017. All rights reserved. No commercial use is permitted unless otherwise expressly granted.

\section{REFERENCES}

1 Scott LJ. Etanercept: a review of its use in autoimmune inflammatory diseases. Drugs 2014:74:1379-410.

2 Enbrel®. Etanercept. Thousand Oaks, CA: Immunex Corporation, 2016.

3 Enbrel® (etanercept). Product characteristics 2016.

$4 \mathrm{Cho} \mathrm{IH}$, Lee N, Song D, et al. Evaluation of the structural, physicochemical, and biological characteristics of SB4, a biosimilar of etanercept. MAbs 2016:8:1136-55.

5 Lee YJ, Shin D, Kim Y, et al. A randomized phase I pharmacokinetic study comparing SB4 and etanercept reference product (Enbrel) in healthy subjects. $\mathrm{Br} J$ Clin Pharmacol 2016:82:64-73. 
6 Emery P, Vencovský J, Sylwestrzak A, et al. A phase III randomised, double-blind, parallel-group study comparing SB4 with etanercept reference product in patients with active rheumatoid arthritis despite methotrexate therapy. Ann Rheum Dis 2017;76:51-7.

7 Vencovsky J, Sylwestrzak A, Leszczynski P, et al. A phase III, randomized, doubleblind clinical study comparing SB4, an etanercept biosimilar, with etanercept reference product (Enbrel) in patients with moderate to severe rheumatoid arthritis despite methotrexate therapy (52-week results) [abstract]. Arthritis Rheumatol 2015;67:2444-6.

8 Benepali®(etanercept). Product characteristics 2016

9 Brenzys $^{\text {TM }}$ (etanercept). Product monograph 2016.

10 van der Heijde D. How to read radiographs according to the sharp/van der Heijde method. J Rheumatol 2000;27:261-3.

11 Emery P, Breedveld F, van der Heijde D, et al. Two-year clinical and radiographic results with combination etanercept-methotrexate therapy versus monotherapy in early rheumatoid arthritis: a two-year, double-blind, randomized study. Arthritis Rheum 2010;62:674-82.

12 Keystone EC, Pope JE, Thorne JC, et al. Two-year radiographic and clinical outcomes from the Canadian methotrexate and etanercept outcome study in patients with rheumatoid arthritis. Rheumatology 2016;55:327-34.

13 van der Heijde D, Klareskog L, Landewé $R$, et al. Disease remission and sustained halting of radiographic progression with combination etanercept and methotrexate in patients with rheumatoid arthritis. Arthritis Rheum 2007;56:3928-39.

14 Dore RK, Mathews S, Schechtman J, et al. The immunogenicity, safety, and efficacy of etanercept liquid administered once weekly in patients with rheumatoid arthritis. Clin Exp Rheumatol 2007;25:40-6.

15 Klareskog L, Gaubitz M, Rodríguez-Valverde V, et al. Assessment of long-term safety and efficacy of etanercept in a 5-year extension study in patients with rheumatoid arthritis. Clin Exp Rheumatol 2011;29:238-47.
16 Weinblatt ME, Schiff MH, Ruderman EM, et al. Efficacy and safety of etanercept $50 \mathrm{mg}$ twice a week in patients with rheumatoid arthritis who had a suboptimal response to etanercept $50 \mathrm{mg}$ once a week: results of a multicenter, randomized, double-blind, active drug-controlled study. Arthritis Rheum 2008;58:1921-30.

17 Yoo DH, Prodanovic N, Jaworski J, et al. Efficacy and safety of CT-P13 (biosimilar infliximab) in patients with rheumatoid arthritis: comparison between switching from reference infliximab to CT-P13 and continuing CT-P13 in the PLANETRA extension study. Ann Rheum Dis 2017:76:355-63.

18 Park W, Yoo DH, Miranda P, et al. Efficacy and safety of switching from reference infliximab to CT-P13 compared with maintenance of CT-P13 in ankylosing spondylitis: 102-week data from the PLANETAS extension study. Ann Rheum Dis 2017;76:346-54

19 Jørgensen KK, Olsen IC, Goll GL, et al. Switching from originator infliximab to biosimilar CT-P13 compared with maintained treatment with originator infliximab (NOR-SWITCH): a 52-week, randomised, double-blind, non-inferiority trial. Lancet 2017;389:2304-16.

20 Glintborg B, Sørensen IJ, Loft AG, et al. A nationwide non-medical switch from originator infliximab to biosimilar CT-P13 in 802 patients with inflammatory arthritis: 1-year clinical outcomes from the DANBIO registry. Ann Rheum Dis 2017;76:1426-31.

21 Glintborg B, Sørensen IJ, Loft AG, et al. Clinical outcomes from a nationwide nonmedical switch from originator to biosimilar etanercept in patients with inflammatory arthritis after 5 months follow-up. Results from the Danbio registry. Ann Rheum Dis 2017;76:553.

22 Sampson HA, Muñoz-Furlong A, Campbell RL, et al. Second symposium on the definition and management of anaphylaxis: summary report--Second National Institute of Allergy and Infectious Disease/Food Allergy and Anaphylaxis Network symposium. J Allergy Clin Immunol 2006;117:391-7. 